JURNAL चEEKNOSAINS

VOLUME 5

No. 1, 22 Desember 2015

Halaman 1-80

\title{
SIMULASI ANTRIAN UNTUK APPOINTMENT SCHEDULING PADA SISTEM PELAYANAN KESEHATAN (STUDI KASUS POLIKLINIK PENYAKIT DALAM)
}

\author{
Diyah Pramita Sari dan Anna Maria Sri Asih \\ Jurusan Teknik Mesin dan Industri \\ Universitas Gadjah Mada \\ Email: diyah.pramita@gmail.com
}

\begin{abstract}
Hospital as a health institution must be able to give good services for its stakeholders, especially patients. However, patients often have to wait for quite a long time in queues before service. A study case in an internal medicine polyclinic in a large scale hospital in Yogyakarta showed that for around 60 patients in a day, they have to stay in queues for more than one hour averagely. This observation occurred when appointment scheduling was used, i.e. patient must make an appointment for the service time. This research evaluated some scenarios that can reduce the waiting time in this system. Results showed that patient's arrival was recommended to be schedulled every 15 minutes with adjustment on the number of operating server. This recommendation can reduce patient's waiting time by $28-50 \%$ by taking into account the presence of the late doctors.
\end{abstract}

Keywords: Appointment scheduling; Health services; Quene; Simulation; Waiting time.

\begin{abstract}
ABSTRAK
Rumah Sakit sebagai salah satu institusi layanan kesehatan dituntut untuk dapat memberikan pelayanan yang terbaik bagi pasien. Salah satu bentuk layanan bagi pasien adalah lamanya waktu tunggu pasien yang sering kali menjadi beban ketika mereka berada di dalam antrian. Di sebuah Poliklinik Penyakit Dalam di salah satu rumah sakit di Yogyakarta, dengan rata-rata jumlah pasien 60 orang per hari, mereka harus mengantri rata-rata lebih dari satu jam. Penelitian ini ditujukan untuk mencari salah satu solusi yang dapat mengurangi waktu tunggu tersebut, yaitu dengan cara mensimulasikan beberapa skenario pada appointment sccheduling yang pada saat ini digunakan. Hasil yang diperoleh menunjukkan bahwa kedatangan pasien direkomendasikan untuk dijadwalkan setiap 15 menit dengan jumlah pasien yang disesuaian dengan jumlah server yang beroperasi, waktu tunggu pasien dapat di kurangi sekitar 28-50\% dengan mempertimbangkan adanya keterlambatan dokter.
\end{abstract}

Kata Kunci: Antrian; Appointment scheduling; Layanan kesehatan; Simulasi;Waktu tunggu. 


\section{PENGANTAR}

Kualitas pelayanan merupakan hal penting yang dijadikan tujuan utama dalam suatu industri pelayanan jasa. Parasuraman dkk (1985) menyatakan kualitas pelayanan didefinisikan sebagai perbedaan antara harapan pelanggan dengan kenyataan yang diterima. Kepuasan merupakan pernyataan psikologi yang dihasilkan dari terpenuhi atau tidaknya harapan dengan pelayanan yang diterima secara nyata (Jackson, 2001).

Industri jasa merupakan sebuah sektor yang berbeda dibanding dengan sektor manufaktur. Sektor manufaktur merupakan industriyang memproses suatu bahan mentah menjadi bahan jadi yang bisa digunakan oleh konsumen. Sedangkan industri jasa merupakan industri yang menghasilkan jasa sebagai output kepada konsumen yang membutuhkan Salah satu contohnya ialah industri pelayanan kesehatan misalnya rumah sakit, klinik, dan puskesmas.

Pengelolaan rumah sakit merupakan proses yang kompleks karena adanya berbagai tujuan yang harus dipenuhi. Sebagai institusi kesehatan, sebuah rumah sakit dituntut untuk selalu memberikan layanan yang terbaik bagi pasiennya dengan selalu memberikan perbaikan terhadap sistem yang ada dan secara berkesinambungan. Salah satu pelayanan dalam rumah sakit diinginkan pasien adalah waktu tunggu pasien yang tidak terlalu lama untuk mendapatkan layanan kesehatan.

Waktu tunggu dapat diartikan sebagai selisih waktu saat seseorang tiba di suatu instansi sampai mendapatkan pelayanan di instansi tersebut (Dexter, 1999). Jika dalam suatu instansi pelayanan kesehatan dalam hal ini rumah sakit,memberikan janji untuk bisa melayani seorang pasien maka sebisa mungkin tepat waktu dari waktu yang dijanjikan sehingga pasien tidak terlalu lama menunggu. Jika rumah sakit tidak bisa menerapkan sistem terbaik sehingga waktu tunggu pasien terlalu lama, hal ini akan menyebabkan pasien merasa tidak puas dan pindah ke rumah sakit lain yang memiliki sistem lebih baik. Dampaknya rumah sakit akan kehilangan pasien dan produktivitas menurun. Peningkatan produktivitas di Poli Rumah Sakit dapat dilakukan dengan mengatasi permasalahan waktu tunggu pasien.

Dalam penelitian yang dilakukan sebelumnya, Gupta dan Danton (2008) menyatakan bahwa terdapat sebuah sistem yang dapat meningkatkan efisiensi dan efektifitas dalam kaitannya dengan waktu tunggu pasien di instansi pelayanan kesehatan. Sistem tersebut adalah dengan appointment scheduling yang dapat memperlancar aliran kerja,mengurangi kepadatan atau antrian yang terjadi di ruang tunggu, dan dapat menyesuaikan supply dan demand dalam sistem di rumah sakit. Penerapan sistem appointment scheduling bertujuan untuk meningkatkan efisiensi dan efektivitas pada poli penyakit dalam, sehingga menurunkan waktu tunggu dan memberikan kepuasan yang lebih baik kepada pasien ketika sistem tersebut diterapkan.

Penelitian terhadap kualitas pelayanan pada rumah sakit dianggap perlu dilakukan. Penelitian ini mengambil objek poliklinik penyakit dalam salah satu rumah sakit di Yogyakarta. Berdasarkan hasil observasi awal, poliklinik penyakit dalam merupakan salah satu poliklinik yang mempunyai jumlah pasien banyak (sekitar 60 pasien perhari) sehingga cukup memakan waktu pasien. Waktu tunggu pasien di Poliklinik Penyakit Dalam di rumah sakit ini rata-rata mencapai lebih dari satu jam. Sistem pendaftaran dari rumah sakit yang bersangkutan sendiri telah menerapkan sistem appointment scheduling, di mana dalam penerapannya pasien sudah bisa melakukan perjanjian via telepon untuk meminimalkan waktu tunggu. Akan tetapi, sistem nyata ini belum mempunyai sistem appointment scheduling yang baik, di mana pasien yang melakukan perjanjian via telepon hanya diberikan nomor urut dan waktu praktik dokter tanpa perkiraan waktu datang pasien, sehingga belum mampu mengatasi permasalahan waktu tunggu pasien.

Penerapan sistem appointment scheduling yang lebih baik pada klinik ini diharapkan 
dapat memberikan waktu tunggu yang lebih pendek sehingga sistem dapat berjalan lebih efektif dan efisien. Penelitian ini dilakukan dengan membuat beberapa alternatif interval kedatangan pasien yang pada akhirnya akan ditarik suatu kesimpulan alternatif yang memiliki optimasi terbaik yang sesuai dengan tujuan penelitian ini.

Penelitian ini menerapkan sistem appointment scheduling dengan objek waktu tunggu dan aktu pelayanan pasien di Poliklinik Penyakit Dalam salah satu rumah sakit di Yogyakarta. Objek ini dipilih karena Poliklinik Penyakit Dalam ini merupakan klinik yang mempunyai jumlah pasien tertinggi dibandingkan klinik yang lainnya di rumah sakit tersebut. Objek penelitian ini memiliki model antrian Multi Channel, Multiphase Systems. Penerapan sistem appointment scheduling ini diharapkan dapat memberikan output waktu tunggu yang paling pendek.

Terdapat delapan tahapan utama penelitian yang dilakukan, sebagaimana terlihat pada Gambar 1, yaitu:

Pada tahap ini dilakukan pengumpulan data berupa data primer dan data sekunder. Data primer diambil dengan melakukan observasi langsung terhadap waktu kedatangan, waktu pelayanan dan waktu proses setiap pasien. Data sekunder didapatkan dengan hasil wawancara dan pengumpulan referensi yang dilakukan sebelumnya.

Pengujian data yang telah diperoleh dengan menguji normalitas data, jika data tidak normal diuji menggunakan goodnesss of fit, kemudian melakukan pengujian hipotesis apakah terdapat perbedaan yang signifikan antara data yang diperoleh.

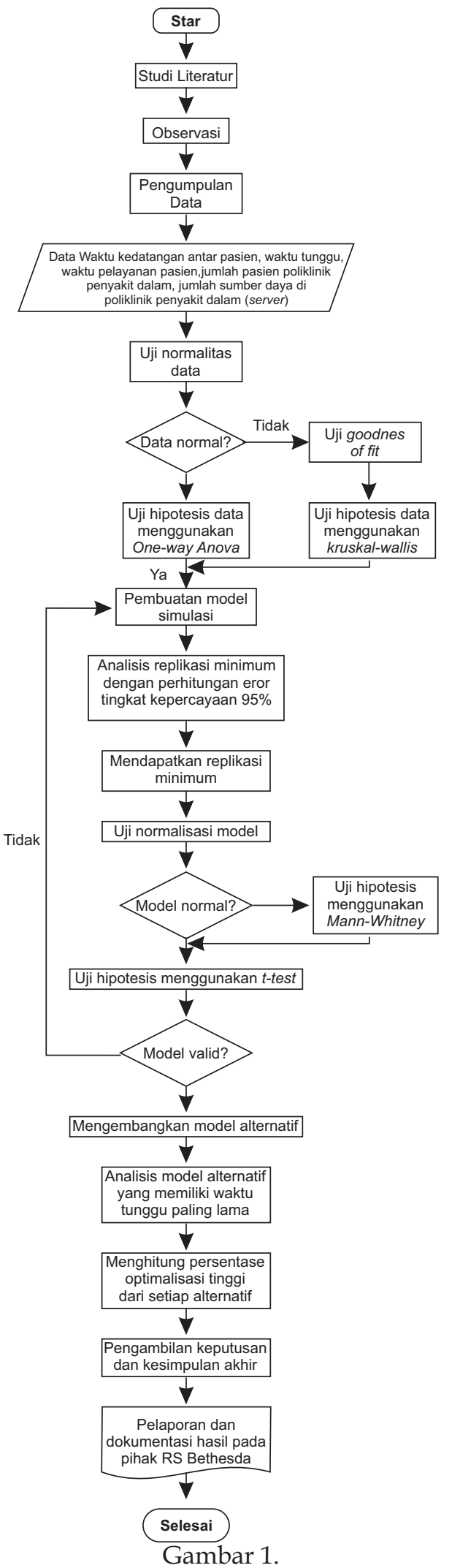

Diagram Alir Penelitian 
Pembuatan model sistem nyata. Data yang telah dikumpulkan dan diuji distribusinya digunakan sebagai input untuk pembuatan model dengan menggunakan software ProModel 4.0. Selanjutnya dibuat pemodelan simulasi untuk pelayanan dengan appointment scheduling.

Pengujian validasi model sistem nyata. Untuk melakukan validitas model, hal pertama yang dilakukan adalah dengan menentukan minimum replikasi yang diperlukan, replikasi awal model sebanyak lima kali. Satu kali replikasi mewakilkan simulasi selama satu hari. Kemudian dilakukan analisis replikasi minimum yang dibutuhkan agar error yang dihasilkan tidak melebihi batas yang diijinkan sesuai dengan tingkat kepercayaan 95\% maka selang kepercayaannya adalah sebagai berikut:

$$
\begin{aligned}
& \theta=Y \pm\left[\left(t_{0,025, R-1} \cdot S\right) / R 1 / 2\right] \\
& \text { dengan : } \\
& \theta \quad \text { : nilai rata-rata sesungguhnya } \\
& \text { Y : nilai rata-rata dari replikasi yang } \\
& \text { telah dibuat } \\
& t_{0,025, \mathrm{R}-1} \text { : batas } t \text { critical yang didapatkan }
\end{aligned}
$$

Tahap awal uji validitas adalah dengan menentukan uji normalitas data dengan uji Kolgomorov-Smirnov atau Shapiro-Wilk. Proses selanjutnya adalah uji hipotesis apakah ada perbedaan yang bermakna antara waktu tunggu sistem nyata dan waktu tunggu model menggunakan uji t-test (jika data terdistribusi normal) atau dengan MannWhitney (jika atau tidak terdistribusi normal).

Membuat model alternatif Model alternatif dibangun menggunakan sistem appointment scheduling atau penjadwalan via telepon sebelumnya sehingga dapat diketahui nomor urut dan kapan pasien tersebut akan dilayani. Hal ini bertujuan untuk mengurangi waktu tunggu pasien. Dengan catatan, jika pasien datang langsung tanpa melakukan pendaftaran via telepon sebelumnya, pasien akan mendapat nomor urut sesuai antrian yang sudah ada atau pasien dialokasikan melakukan penjadwalan dihari berikutnya (jika kuota dokter sudah penuh di hari itu).

Modelalternatif dibangunmenggunakan beberapa alternatif untuk tiga model yang telah dibuat, yaitu:

Kelompok model 2 Server, terdapat 9 alternatif perbaikan dengan penjelasan pada Tabel 1. Pada alternatif 2-9 alternatif ini dilakukan untuk mengatasi kemungkinan jika pasien terlambat datang/pasien tidak datang tepat waktu sehingga menyebabkan terjadinya waktu senggang Server. Contoh: pasien dengan urutan pertama sudah selesai dengan waktu kurang dari 8 menit (ratarata waktu pelayanan), sedangkan pasien selanjutnya belum/terlambat datang hal ini akan menyebabkan waktu tunggu pasien akan semakin lama. Mekanisme pada alternatif 2-9 ini menerapkan First Come First Serve (FCFS) di mana pasien akan dilayani sesuai dengan nomor urut pasien.

Kelompok model 3 Server, terdapat 9 alternatif perbaikan dengan penjelasan pada Tabel 2.

Kelompok model khusus hari Jumat untuk Poliklinik Penyakit Dalam. Pembuatan alternatif ini perlu dilakukan karena pada Poliklinik Penyakit Dalam untuk Hari Jumat terdapat perbedaan kedatangan jumlah pasien yang jauh lebih sedikit dibandingkan hari hari yang lain,namun ada tiga dokter (Server) yang praktik. Hal ini menyebabkan diperlukannya pembuatan model dan alternatif khusus Hari Jumat untuk Poli Penyakit Dalam. Terdapat delapan alternatif perbaikan dengan penjelasan pada Tabel 3.

Tabel 1. Penyusunan Alternatif Perbaikan Kelompok Model 2 Server

\begin{tabular}{l|l}
\hline $\begin{array}{c}\text { Alter- } \\
\text { natif }\end{array}$ & \multicolumn{1}{c}{ Keterangan } \\
\hline 1 & $\begin{array}{l}\text { Pasien dijadwalkan datang berdasarkan } \\
\text { waktu rata-rata pelayanan dokter setiap } \\
8 \text { menit. Pada alternatif ini pasien akan } \\
\text { dilayani dari nomor urut paling kecil }\end{array}$ \\
\hline 2 & $\begin{array}{l}\text { Kedatangan pasien tetap mengikuti rata- } \\
\text { rata waktu pelayanan pada kondisi nyata. } \\
\text { Dimana setiap 15 menit terdapat empat } \\
\text { kedangan pasien }\end{array}$ \\
\hline
\end{tabular}


DIYAH PRAMITA SARI DAN ANNA MARIA SRI ASIH $\$$ SIMULASI ANTRIAN UNTUK APPOINTMENT SCHEDULING PADA SISTEM PELAYANAN KESEHATAN...

\begin{tabular}{l|l}
$\begin{array}{c}\text { Lanjutan Tabel 1 } \\
\text { Alter- } \\
\text { natif }\end{array}$ & \multicolumn{1}{c}{ Keterangan } \\
\hline 3 & $\begin{array}{l}\text { Kedatangan pasien tetap mengikuti rata- } \\
\text { rata waktu pelayanan pada kondisi nyata. } \\
\text { Dimana setiap 30 menit terdapat delapan } \\
\text { kedatangan pasien }\end{array}$ \\
\hline 4 & $\begin{array}{l}\text { Kedatangan pasien tetap mengikuti } \\
\text { rata-rata waktu pelayanan pada kondisi } \\
\text { nyata. Dimana setiap 45 menit terdapat 12 } \\
\text { kedatangan pasien }\end{array}$ \\
\hline 5 & $\begin{array}{l}\text { Kedatangan pasien dimana setiap 15 menit } \\
\text { dengan jumlah kedatangan mengikuti } \\
\text { distribusi jumlah kedatangan pasien pada } \\
\text { sistem nyata. }\end{array}$ \\
\hline 6 & $\begin{array}{l}\text { Kedatangan pasien dimana setiap 30 menit } \\
\text { dengan jumlah kedatangan mengikuti } \\
\text { distribusi jumlah kedatangan pasien pada } \\
\text { sistem nyata. }\end{array}$ \\
\hline 7 & $\begin{array}{l}\text { Kedatangan pasien dimana setiap 45 menit } \\
\text { dengan jumlah kedatangan mengikuti } \\
\text { distribusi jumlah kedatangan pasien pada } \\
\text { sistem nyata. }\end{array}$ \\
\hline 8 & $\begin{array}{l}\text { Kedatangan pasien dimana setiap } 60 \text { menit } \\
\text { dengan jumlah kedatangan mengikuti } \\
\text { distribusi jumlah kedatangan pasien pada } \\
\text { sistem nyata. }\end{array}$ \\
\hline $\begin{array}{l}\text { Frekuensi kedatangan pasien mengikuti } \\
\text { distribusi waktu pemeriksaan pasien } \\
\text { pada sistem nyata bukan rata-rata waktu } \\
\text { pemeriksaan pasien }\end{array}$ \\
\hline 9
\end{tabular}

Tabel 2. Penyusunan Alternatif Perbaikan Kelompok Model 3 Server

\begin{tabular}{l|l}
\hline $\begin{array}{c}\text { Alter- } \\
\text { natif }\end{array}$ & \multicolumn{1}{|c}{ Keterangan } \\
\hline 1 & $\begin{array}{l}\text { Pasien dijadwalkan datang berdasarkan } \\
\text { waktu rata-rata pelayanan dokter setiap } \\
8 \text { menit. Pada alternatif ini merupakan } \\
\text { mekanisme First Come First Serve (FCFS) } \\
\text { dimana pasien akan dilayani dari nomor } \\
\text { urut pasien }\end{array}$ \\
\hline 2 & $\begin{array}{l}\text { Kedatangan pasien tetap mengikuti rata- } \\
\text { rata waktu pelayanan pada kondisi nyata. } \\
\text { Dimana setiap 15 menit terdapat lima } \\
\text { kedangan pasien }\end{array}$ \\
\hline 3 & $\begin{array}{l}\text { Kedatangan pasien tetap mengikuti } \\
\text { rata-rata waktu pelayanan pada kondisi } \\
\text { nyata. Dimana setiap 30 menit terdapat 10 } \\
\text { kedatangan pasien }\end{array}$ \\
\hline 4 & $\begin{array}{l}\text { Kedatangan pasien tetap mengikuti } \\
\text { rata-rata waktu pelayanan pada kondisi } \\
\text { nyata. Dimana setiap 45 menit terdapat 15 } \\
\text { kedatangan pasien }\end{array}$ \\
\hline
\end{tabular}

\begin{tabular}{l|l}
$\begin{array}{c}\text { Lanjutan Tabel 2 } \\
\text { Alter- } \\
\text { natif }\end{array}$ & \multicolumn{1}{c}{ Keterangan } \\
\hline 5 & $\begin{array}{l}\text { Kedatangan pasien dimana setiap 15 menit } \\
\text { dengan jumlah kedatangan mengikuti } \\
\text { distribusi jumlah kedatangan pasien pada } \\
\text { sistem nyata. }\end{array}$ \\
\hline 6 & $\begin{array}{l}\text { Kedatangan pasien dimana setiap 30 menit } \\
\text { dengan jumlah kedatangan mengikuti } \\
\text { distribusi jumlah kedatangan pasien pada } \\
\text { sistem nyata. }\end{array}$ \\
\hline 7 & $\begin{array}{l}\text { Kedatangan pasien dimana setiap 45 menit } \\
\text { dengan jumlah kedatangan mengikuti } \\
\text { distribusi jumlah kedatangan pasien pada } \\
\text { sistem nyata. }\end{array}$ \\
\hline 8 & $\begin{array}{l}\text { Kedatangan pasien dimana setiap 60 menit } \\
\text { dengan jumlah kedatangan mengikuti } \\
\text { distribusi jumlah kedatangan pasien pada } \\
\text { sistem nyata. }\end{array}$ \\
\hline 9 & $\begin{array}{l}\text { Frekuensi kedatangan pasien mengikuti } \\
\text { distribusi waktu pemeriksaan pasien pada } \\
\text { sistem nyata bukan waktu rata-rata pasien }\end{array}$ \\
\hline
\end{tabular}

Tabel 3. Penyusunan Alternatif Perbaikan Kelompok Model Khusus Hari Jumat

\begin{tabular}{l|l}
\hline $\begin{array}{c}\text { Alter- } \\
\text { natif }\end{array}$ & \multicolumn{1}{c}{ Keterangan } \\
\hline 1 & $\begin{array}{l}\text { Pasien dijadwalkan datang berdasarkan } \\
\text { waktu rata-rata pelayanan dokter setiap } \\
8 \text { menit. Pada alternatif ini merupakan } \\
\text { mekanisme First Come First Serve (FCFS) } \\
\text { dengan pasien nomor urut kecil akan } \\
\text { dilayani lebih dulu }\end{array}$ \\
\hline 2 & $\begin{array}{l}\text { Kedatangan pasien tetap mengikuti rata- } \\
\text { rata waktu pelayanan pada kondisi nyata. } \\
\text { Dimana setiap 15 menit terdapat dua } \\
\text { kedangan pasien }\end{array}$ \\
\hline 3 & $\begin{array}{l}\text { Kedatangan pasien tetap mengikuti rata- } \\
\text { rata waktu pelayanan pada kondisi nyata. } \\
\text { Dimana setiap 30 menit terdapat empat } \\
\text { kedatangan pasien }\end{array}$ \\
\hline 4 & $\begin{array}{l}\text { Kedatangan pasien tetap mengikuti rata- } \\
\text { rata waktu pelayanan pada kondisi nyata. } \\
\text { Dimana setiap 45 menit terdapat enam } \\
\text { kedatangan pasien }\end{array}$ \\
\hline 5 & $\begin{array}{l}\text { Kedatangan pasien dimana setiap 15 menit } \\
\text { dengan jumlah kedatangan mengikuti } \\
\text { distribusi jumlah kedatangan pasien pada } \\
\text { sistem nyata. }\end{array}$ \\
\hline 6 & $\begin{array}{l}\text { Kedatangan pasien dimana setiap 30 menit } \\
\text { denganjumlah kedatangan mengikuti distribusi } \\
\text { jumlah kedatangan pasien pada sistem nyata. }\end{array}$ \\
\hline & \\
\hline
\end{tabular}


Lanjutan Tabel 3

\begin{tabular}{l|l}
\hline $\begin{array}{c}\text { Alter- } \\
\text { natif }\end{array}$ & \multicolumn{1}{c}{ Keterangan } \\
\hline 7 & $\begin{array}{l}\text { Kedatangan pasien dimana setiap 60 menit } \\
\text { dengan jumlah kedatangan mengikuti } \\
\text { distribusi jumlah kedatangan pasien pada } \\
\text { sistem nyata. }\end{array}$ \\
\hline 9 & $\begin{array}{l}\text { Frekuensi kedatangan pasien mengikuti } \\
\text { distribusi waktu pemeriksaan pasien pada } \\
\text { sistem nyata bukan waktu rata-rata pasien }\end{array}$ \\
\hline
\end{tabular}

Analisis Model Alternatif. Setelah dilakukan pembuatan alternatif, kemudian alternatif tersebut harus dibandingkan satu sama lain dengan parameter waktu tunggu dan jumlah pasien. Analisis dimulai setelah masing masing alternatif dijalankan dengan 20 replikasi.

Menghitung Persentase Optimasi dari Setiap Alternatif. Setelah beberapa alternatif perbaikan didapatkan, kemudian alternatif tersebut dibandingkan satu dengan yang lainnya untuk didapatkan hasil yang paling optimal. Alternatif terbaik adalah alternatif yang memiliki waktu tunggu pasien paling rendah serta tingkat efisiensi paling tinggi. Tahapan penghitungan optimasi untuk mendapatkan tingkat efisiensi pengurangan waktu tunggu paling tinggi yaitu:

a. Menghitung total waktu tunggu (hr) yang dihabiskan oleh pasien pada sistem nyata dan model altenatif yang telah dipilih: Jumlah pasien $\times$ Waktu Tunggu pasien (hr) = total waktu tunggu pasien pada sistem nyata (hr)

b. Menghitung selisih antara waktu tunggu sistem nyata dengan model

c. Menghitung optimasi waktu tunggu dengan cara:

$$
\frac{\text { Selisih Waktu Tunggu }}{\text { Total Waktu Tunggu pada Sistem Nyata }} \text { X100 }
$$

Pengambilan Keputusan dan Kesimpulan Akhir. Kesimpulan diambil setelah alternatif terbaik didapat yaitu alternatif yang memiliki nilai optimasi paling tinggi.
Alternatif optimal yang sesuai dengan tujuan penelitian ini yaitu sistem appointment scheduling yang paling optimal untuk meminimasi antrian sehingga menghasilkan waktu tunggu yang paling pendek pada Poliklinik Penyakit Dalam.

\section{HASIL DAN PEMBAHASAN Deskripsi Sistem}

Gambar 2 menunjukkan alur sistem yang ditinjau. Sistem antrian di rumah sakit yang diteliti ini menerapkan sistem FCFS (First Come First Serve) tanpa mempertimbangkan kondisi pasien namun lebih memprioritaskan pasien yang sudah melakukan perjanjian via telepon. Jadi, pasien langsung yang sudah datang lebih awal bukan berarti akan mendapatkan pelayanan dokter lebih cepat namun akan dilayani sesuai dengan pasien yang memilikiangka urutan kecil.Pasien yang telah melakukan pendaftaran via telepon dilakukan minimal sebulan sebelumnya dan maksimal sehari sebelum pasien datang ke rumah sakit. Pasien yang dalam keadaan darurat akan langsung dilayani oleh Instalasi Gawat Darurat (IGD). Pasien yang datang langsung bisa mendapatkan pelayanan dokter jika pasien perjanjian belum datang dan pada kenyataannya beberapa pasien yang telah melakukan pendaftaran via telepon tidak seluruhnya datang ke poliklinik untuk diperiksa.

Pada Poliklinik rumah sakit yang diteliti ditemukan permasalahan penting mengenai waktu tunggu pasien. Pasien yang telah mendaftar via telepon hanya diberitahukan slot hari dan jam praktek dokter tanpa ada alokasi jam kedatangan untuk pasien, sehingga seringkali ketika pasien datang, masih harus menunggu hingga waktu yang belum pasti. Pasien hanya diberikan nomor antrian dan diminta datang sesuai dengan jam praktek dokternya, sehingga sering terjadi penumpukan pasien yang menyebabkan waktu tunggu yang cukup lama bagi pasien. 
DIYAH PRAMITA SARI DAN ANNA MARIA SRI ASIH $\$$ SIMULASI ANTRIAN UNTUK APPOINTMENT SCHEDULING PADA SISTEM PELAYANAN KESEHATAN...

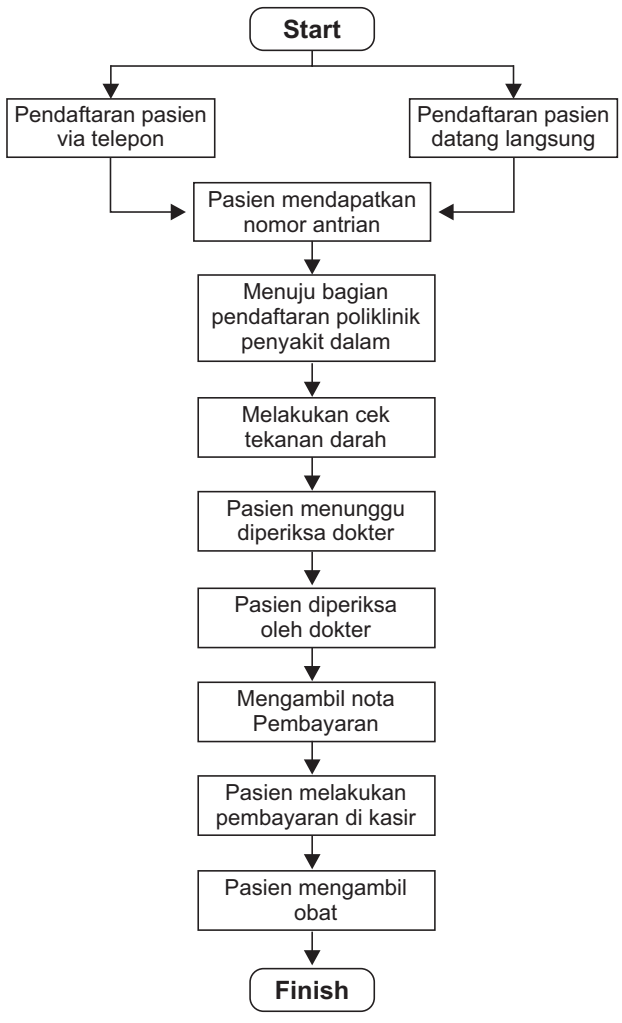

Gambar 2.

Alur Pemeriksaan Pasien Klinik Penyakit Dalam

\section{Pengambilan Data dan Verifikasi Data}

Proses pengambilan data dilakukan selama dua bulan dimulai sejak bulan Januari 2014 hingga Maret 2014. Dari hasil observasi didapatkan data interarrival kedatangan pasien dan waktu pelayanan/pemeriksaan dokter.

Proses verifikasi data input yang akan digunakan untuk dijadikan input pada pembuatan simulasi model, dengan hasil uji signifikansi One-way Anova terhadap rata-rata jumlah pasien perharinya ada pada Tabel 4.

Tabel 4. Uji Signifikansi One-Way Anova

\begin{tabular}{l|c|c|c|c|c}
\hline & $\begin{array}{c}\text { Sum of } \\
\text { Square }\end{array}$ & df & $\begin{array}{c}\text { Mean } \\
\text { Square }\end{array}$ & F & Sig \\
\hline $\begin{array}{l}\text { Between } \\
\text { Groups } \\
\text { Within }\end{array}$ & 3592.000 & 2 & 718.400 & 6.003 & 0.002 \\
$\begin{array}{l}\text { Group } \\
\text { Total }\end{array}$ & 5746.000 & 18 & 119.667 & & \\
\hline
\end{tabular}

Pada Tabel4 didapatkannilai signifikansi sebesar 0,156 hal ini dapat diartikan bahwa data memiliki keragaman atau varian yang sama. Sedangkan pada Tabel 4 uji One-Way Anova memiliki nilai signifikansi 0,002 atau kurang daripada $\alpha=0,05$ dan dapat disimpulkan bahwa ada perbedaan jumlah pasien perharinya. Hal ini dikarenakan perbedaan jumlah dokter yang praktek tiap harinya, dalam satu minggu pada poliklinik penyakit dalam di hari Senin, Selasa, dan Sabtu ada dua dokter (Server) yang praktik, sedangkan di hari Rabu, Kamis, dan Jumat

Terdapat tiga dokter (Server) yang praktik. Sehingga dapat dikelompokkan:

b. 2 Server (Senin, Selasa, dan Sabtu) mengikuti distribusi Pareto $(46 ; 8,25)$.

c. 3 Server (Rabu, Kamis dan Jumat) mengikuti distribusi Beta $(24,73 ; 0,71 ; 1.45)$.

Untuk interarrival kedatangan pasien setiap kelompok Server mengikuti distribusi: a. 2 Server (Senin,Selasa dan Sabtu) mengikuti distribusi Pearson 6 (0; 11,5; 0,965; $3,92)$.

b. 3 Server (Rabu, Kamis, dan Jumat) mengikuti distribusi Gamma (0; 0,775; 6,57).

Sedangkan untuk waktu pelayanan dokter mengikuti distribusi Gamma ( $1 ; 3,18$; 2,02 ) untuk semua kelompok Server.

\section{Pembuatan Model Sistem Nyata}

Pembuatan model ini bertujuan untuk mendapatkan gambaran mengenai sistem nyata dari poliklinik yang diteliti sehingga dapat diukur performansi sistem nyata dan mencari alternatif yang paling optimal.Pembuatan model ini menggunakan software Promodel 4.2 dengan input data interarrival kedatangan pasien dan waktu pelayanan dokter.

Batasan dibuat agar model lebih merepresentasikan sistem nyata dan lebih fokus pada permasalahan yang ditemui. Berikut merupakan batasan model ini:

a. Model sistem dibedakan menjadi dua macam (dua Server dan tiga Server) sesuai dengan jumlah dokter (Server) yang praktek tiap harinya.

b. Parameter-parameter ini berdasarkan waktu tunggu,waktu pelayanan dan jumlah pasien tidak terkait dengan biaya. 
c. Satuan waktu yang digunakan dalam model adalah satuan menit.

d. Parameter validasi model berdasarkan pendekatan uji statistik.

e. Sistem dalam model membatasi pelayanan dokter hanya sampai pukul 13.00, jika pada saat pelayanan dokter selesai dan pasien masih ada yang belum terlayani (berada pada ruang tunggu) maka pasien tersebut masih mendapat pelayanan dokter.

Asumsi yang digunakan dalam model adalah sebagai berikut.

a. Sistem disimulasikan mulai pukul 07.0013.00 sesuai dengan shift pagi di poliklinik penyakit dalam. Namun, pada keadaan nyatanya praktek dokter mulai pukul 09.00 - 13.00 WIB dan sebelum jam praktek dimulai pasien sudah banyak yang datang. Hal ini menyebabkan praktek dokter tidak dapat tutup tepat waktu, poliklinik akan tutup sampai semua pasien dilayani. b. Pasien yang datang lebih dari pukul 13.00 sudah tidak dapat dilayani.

c. Jumlah kedatangan pasien, waktu interarrival kedatangan pasien, dan waktu pelayanan dokter dianggap mengikuti distribusi statistik berdasarkan observasi.

d. Proses pengecekan tekanan darah (tensi) hanya berlangsung 3 menit sehingga dianggap tidak mempengaruhi waktu tunggu.

e. Proses pelayanan dokter dimulai tepat pukul 09.00-13.00, dokter diasumsikan selalu datang tepat waktu.

f. Pasien yang keluar dari ruang periksa dianggap langsung keluar dari sistem.

Setelah model dibuat, dilakukan analisis dengan parameter yang digunakan pada penelitian kali ini adalah waktu tunggu pasien, oleh karena itu yang dijadikan pengamatan utama adalah location state pada report Promodel 4.2. Hasil report untuk masing-masing kelompok Server dapat dilihat dari Tabel 5 dan 6 berikut ini.

Tabel 5. Report Waktu Tunggu untuk Location State

\begin{tabular}{l|l|l|l|l}
\hline \multicolumn{1}{c|}{ Location } & Schedule Hours & Capacity & Total Entries & Average Minutes Per Entry \\
\hline $\begin{array}{l}\text { Ruang Tunggu } \\
\text { (2 Server) }\end{array}$ & $5,55 \mathrm{hr}$ & INF & 51,73 orang & $80,96 \mathrm{~min}$ \\
$\begin{array}{l}\text { Ruang Tunggu } \\
\text { (3 Server) }\end{array}$ & $5,17 \mathrm{hr}$ & INF & 53,87 orang & $86,39 \mathrm{~min}$ \\
\hline
\end{tabular}

Tabel 6. Rata-rata Waktu Total Pasien dalam Sistem

\begin{tabular}{l|l|l}
\hline & \multicolumn{1}{|c|}{ Total Exits } & \multicolumn{1}{c}{ Minutes In Systems } \\
\hline Pasien Selesai (2 Server) & 50,8 orang & $94,75 \mathrm{~min}$ \\
\hline Pasien Selesai (3 Server) & 53,33 orang & $99,04 \mathrm{~min}$ \\
\hline
\end{tabular}

Pada Tabel 5 dan 6 di atas dapat dilihat bahwa total waktu tunggu pasien masih sangat tinggi yaitu sekitar 80 menit. Dapat disimpulkan bahwa sekitar $85 \%$ dari total waktu pasien pada sistem dialokasikan untuk waktu tunggu pelayanan.

\section{Pengembangan Alternatif Perbaikan Sistem}

\section{Alternatif Perbaikan Dua Server}

Alternatif perbaikan dilakukan setelah model sistem dibuat dan dapat merepresentasikan sistem nyata. Alternatif perbaikan dilakukan dengan melakukan eksperimen untuk mendapatkan sistem yang optimal sesuai model yang dibangun.

Alternatif dilakukan dengan mengatur waktu kedatangan pasien yang telah melakukan perjanjian sebelumnya. Sekitar 90\% pasien Poliklinik Penyakit Dalam telah melakukan perjanjian sebelumnya, namun belum ada pengaturan jadwal kedatangan pasien sehingga pasien hanya mengasumsi sendiri kedatangannya sehingga waktu tunggu pasien cukup lama. Untuk itu dilakukan penjadwalan kedatangan pasien yang paling optimal untuk meminimalkan waktu tunggu pasien. 
Pada setiap alternatif, model dijalankan selama empat jam dari pukul 09.00 - 13.00 dan kedatangan awal pasien pada pukul 09.00.

\section{Alternatif Perbaikan Tiga Server}

Setelah dilakukan pembuatan alternatif didapatkan sembilan alternatif perbaikan, kemudian dari sembilan alternatif tersebut harus dibandingkan dan dilihat untuk mendapatkan hasil akhir yang terbaik sesuai dengan tujuan awal yakni mendapatkan sistem appointment scheduling atau penjadwalan kedatangan pasien yang paling optimal untuk mengurangi waktu tunggu pada poliklinik penyakit dalam. Tabel 8 merupakan hasil alternatif untuk kelompok 3 Server setelah model dijalankan dengan replikasi sebanyak 20 kali.

Tabel 7. Hasil Alternatif Perbaikan untuk Kelompok 2 Server

\begin{tabular}{l|l|l|l}
\hline no & \multicolumn{1}{|c|}{ Pilihan Alternatif } & $\begin{array}{l}\text { Rata-rata Waktu } \\
\text { Tunggu (min) }\end{array}$ & $\begin{array}{l}\text { Jumlah Pasien } \\
\text { yang Terlayani }\end{array}$ \\
\hline 1 & Kedatangan Pasien setiap 4 menit & 8,8 & 52 \\
\hline 2 & Kedatangan Pasien 4 pasien/15 menit & 10,79 & 64 \\
\hline 3 & Kedatangan Pasien 8 pasien/30 menit & 12,82 & 64 \\
\hline 4 & Kedatangan Pasien 12 pasien/45 menit & 14,76 & 64 \\
\hline 5 & $\begin{array}{l}\text { Kedatangan Pasien setiap 15 menit ; mengikuti distribusi } \\
\text { jumlah kedatangan pasien }\end{array}$ & 3,94 & 39 \\
\hline 6 & $\begin{array}{l}\text { Kedatangan Pasien setiap 30 menit ; mengikuti distribusi } \\
\text { jumlah kedatangan pasien }\end{array}$ & 6,98 & 44 \\
\hline 7 & $\begin{array}{l}\text { Kedatangan Pasien setiap 45 menit ; mengikuti distribusi } \\
\text { jumlah kedatangan pasien }\end{array}$ & 8,58 & 44 \\
\hline 8 & $\begin{array}{l}\text { Kedatangan Pasien setiap 60 menit ; mengikuti distribusi } \\
\text { jumlah kedatangan pasien }\end{array}$ & 11,23 & 44 \\
\hline 9 & $\begin{array}{l}\text { Kedatangan 2 Pasien dengan frekuensi ; mengikuti } \\
\text { distribusi waktu pelayanan (2 server) }\end{array}$ & 10,97 & 63 \\
\hline
\end{tabular}

Tabel 8. Hasil Alternatif Perbaikan untuk Kelompok 3 Server

\begin{tabular}{l|l|l|l}
\hline no & \multicolumn{1}{|c|}{ Pilihan Alternatif } & $\begin{array}{l}\text { Rata-rata Waktu } \\
\text { Tunggu (min) }\end{array}$ & $\begin{array}{l}\text { Jumlah Pasien } \\
\text { yang Terlayani }\end{array}$ \\
\hline 1 & Kedatangan Pasien setiap 3 menit & 12,83 & 56 \\
\hline 2 & Kedatangan Pasien 5 pasien/15 menit & 12,027 & 80 \\
\hline 3 & Kedatangan Pasien 10 pasien/30 menit & 13,84 & 80 \\
\hline 4 & Kedatangan Pasien 15 pasien/45 menit & 15,08 & 86 \\
\hline 5 & $\begin{array}{l}\text { Kedatangan Pasien setiap 15 menit mengikuti distribusi } \\
\text { jumlah kedatangan pasien }\end{array}$ & 6,53 & 58 \\
\hline 6 & $\begin{array}{l}\text { Kedatangan Pasien setiap 30 menit mengikuti distribusi } \\
\text { jumlah kedatangan pasien }\end{array}$ & 8,04 & 58 \\
\hline 7 & $\begin{array}{l}\text { Kedatangan Pasien setiap 45 menit mengikuti distribusi } \\
\text { jumlah kedatangan pasien }\end{array}$ & 10,9 & 64 \\
\hline 8 & $\begin{array}{l}\text { Kedatangan Pasien setiap 60 menit mengikuti distribusi } \\
\text { jumlah kedatangan pasien }\end{array}$ & 12,18 & 59 \\
\hline 9 & $\begin{array}{l}\text { Kedatangan 3 Pasien dengan frekuensi mengikuti } \\
\text { distribusi waktu pelayanan (3 server) }\end{array}$ & 14,82 & 90 \\
\hline
\end{tabular}

\section{Analisis Alternatif Hari Jumat (khusus} poliklinik penyakit dalam)

Alternatif ini perlu dilakukan karena pada poliklinik penyakit dalam untuk hari Jumat terdapat perbedaan jumlah pasien yang jauh lebih sedikit dibandingkan hari hari yang tetapi, namun terdapat tiga dokter (Server) yang praktik. Hal ini menyebabkan diperlukannya pembuatan model dan alternatif khusus Hari Jumat untuk poli 
penyakit dalam. Dalam pembuatan modelnya tidak berbeda jauh dengan model sebelumnya, perbedaanya hanya terletak pada distribusi jumlah pasien dan interarrival kedatangannya, dimana jumlah pasien mengikuti distribusi uniform $(19,30)$ dan interarrival kedatangan pasien mengikuti distribusi log-logistic $(0 ; 1,17 ; 4,57)$.

Dari ketiga kelompok perbaikan diatas, dapat disimpulkan alternatif 5 dari masing masing kelompok Server adalah alternatif yang mempunyai waktu tunggu pasien paling pendek.

Tabel 9. Hasil Alternatif Perbaikan untuk Hari Jumat

\begin{tabular}{l|l|l|l}
\hline no & \multicolumn{1}{|c|}{ Pilihan Alternatif } & $\begin{array}{l}\text { Rata-rata Waktu } \\
\text { Tunggu (min) }\end{array}$ & $\begin{array}{l}\text { Jumlah Pasien } \\
\text { yang Terlayani }\end{array}$ \\
\hline 1 & Kedatangan Pasien setiap 4 menit & 4,69 & 24 \\
\hline 2 & Kedatangan Pasien 2 pasien/15 menit & 1,93 & 32 \\
\hline 3 & Kedatangan Pasien 4 pasien/30 menit & 3,47 & 32 \\
\hline 4 & Kedatangan Pasien 6 pasien/45 menit & 5,03 & 36 \\
\hline 5 & $\begin{array}{l}\text { Kedatangan Pasien setiap 15 menit mengikuti distribusi } \\
\text { jumlah kedatangan pasien }\end{array}$ & 1,77 & 21 \\
\hline 6 & $\begin{array}{l}\text { Kedatangan Pasien setiap 30 menit mengikuti distribusi } \\
\text { jumlah kedatangan pasien }\end{array}$ & 2,71 & 20 \\
\hline 7 & $\begin{array}{l}\text { Kedatangan Pasien setiap 60 menit mengikuti distribusi } \\
\text { jumlah kedatangan pasien }\end{array}$ & 4,51 & 22 \\
\hline 8 & $\begin{array}{l}\text { Kedatangan 3 Pasien dengan frekuensi mengikuti } \\
\text { distribusi waktu pelayanan (3 server) }\end{array}$ & 15,18 & 72 \\
\hline
\end{tabular}

\section{Validasi Model Optimasi dengan Sistem Nyata}

Setelah proses pemilihan alternatif terbaik dilakukan, langkah selanjutnya yaitu menguji apakah alternatif yang telah dipilih benar-benar merepresentasikan sistem nyata dan feasible untuk diterapkan. Pada kondisi model alternatif, dokter diasumsikan datang tepat waktu/tidak terlambat, sedangkan pada kondisi riilnya rata-rata dokter mengalami keterlambatan selama 40-60 menit sehingga waktu tunggu pasien menjadi sangat lama. Untuk itu dilakukan pengujian alternatif dengan menambahkan parameter waktu keterlambatan dokter.

Berdasarkan data kondisi nyata waktu keterlambatan dokter mengikuti distribusi pearson 5 dengan nilai $\min =; 20$, alpha $=4,95$, beta $=137,5$. Setelah dilakukan penambahan parameter waktu keterlambatan dokter pada alternatif yang dipilih agar sesuai dengan sistem nyata, langkah selanjutnya yaitu menganalisis apakah alternatif tersebut feasible atau layak diterapkan. Hal ini dilakukan dengan alasan hasil perhitungan optimasi model alternatif pada sub bab sebelumnya menunjukkan tingkat optimasi yang sangat besar 90\%-96\% dengan asumsi tidak ada waktu keterlambatan dokter. Oleh karena itu, pengujian kelayakan model alternatif dilakukan dengan menambahkan parameter tersebut sehingga dapat dilihat seberapa besar perbedaannya jika asumsi awal dihilangkan.

Alternatif 5 adalah dari masing-masing kelompok menjadi alternatif yang paling optimal dan feasible untuk diterapkan.

Tabel 10. Persentase Optimasi Akhir Alternatif Terbaik

\begin{tabular}{|c|c|c|c|}
\hline \multirow[t]{2}{*}{ Kelompok Server } & \multicolumn{2}{|c|}{ Alternatif 5} & \multirow[t]{2}{*}{$\%$ Selisih } \\
\hline & $\begin{array}{c}\text { Dokter diasumsikan datang } \\
\text { tepat waktu }\end{array}$ & $\begin{array}{l}\text { Waktu Keterlambatan Dokter } \\
\text { (sesuai kondisi riil) }\end{array}$ & \\
\hline 2 Server & $95 \%$ & $50 \%$ & $45 \%$ \\
\hline 3 Server & $90 \%$ & $49 \%$ & $41 \%$ \\
\hline Jumat & $96 \%$ & $25 \%$ & $68 \%$ \\
\hline
\end{tabular}


DIYAH PRAMITA SARI DAN ANNA MARIA SRI ASIH $\$$ SIMULASI ANTRIAN UNTUK APPOINTMENT SCHEDULING PADA SISTEM PELAYANAN KESEHATAN...

Pada Tabel 10 di atas dapat disimpulkan akan terjadi penambahan waktu tunggu pasien sekitar $4060 \%$ yang disebabkan karena keterlambatan kedatangan dokter. Jika dokter dapat datang tepat waktu/tidak terlambat dari jadwal, maka waktu tunggu pasien akan lebih sedikit.

Hasil akhir simulasi antrian pasien untuk appointment scheduling pada poliklinik penyakit dalam ditunjukkan pada Tabel 1113.

Tabel 11. Kedatangan Pasien untuk Kelompok Dua Server

\begin{tabular}{l|l|l|l}
\hline No & $\begin{array}{c}\text { Interval } \\
\text { Kedatangan }\end{array}$ & \multicolumn{1}{|c}{$\begin{array}{c}\text { Urutan } \\
\text { Pasien }\end{array}$} & Total Pasien \\
\hline 1 & $9.00-9.15$ & 1 s.d 3 & 3 \\
\hline 2 & $9.16-9.30$ & 4 s.d 5 & 2 \\
\hline 3 & $9.31-9.45$ & 6 s.d 7 & 2 \\
\hline 4 & $9.46-10.00$ & 8 s.d 10 & 3 \\
\hline 5 & $10.01-10.15$ & 11 s.d 13 & 3 \\
\hline 6 & $10.16-10.30$ & 14 & 1 \\
\hline 7 & $10.31-10.45$ & 15 s.d 17 & 3 \\
\hline 8 & $10.46-11.00$ & 18 s.d 19 & 2 \\
\hline 9 & $11.01-11.15$ & 20 s.d 22 & 3 \\
\hline 10 & $11.16-11.30$ & 23 s.d 24 & 2 \\
\hline 11 & $11.31-11.45$ & 25 s.d 27 & 3 \\
\hline 12 & $11.46-12.00$ & 28 s.d 29 & 2 \\
\hline 13 & $12.01-12.15$ & 30 s.d 31 & 2 \\
\hline 14 & $12.16-12.30$ & 32 s.d 33 & 2 \\
\hline 15 & $12.31-12.45$ & 34 s.d 36 & 3 \\
\hline 16 & $12.46-13.00$ & 37 s.d 38 & 3 \\
\hline
\end{tabular}

Tabel 12. Kedatangan Pasien untuk Kelompok Tiga Server

\begin{tabular}{l|l|l|l}
\hline No & \multicolumn{1}{|c|}{ Interval } & \multicolumn{1}{|c}{$\begin{array}{c}\text { Urutan } \\
\text { Pasien }\end{array}$} & \multicolumn{1}{|c}{$\begin{array}{c}\text { Total } \\
\text { pasien }\end{array}$} \\
\hline 1 & $9.00-9.15$ & 1 s.d 4 & 4 \\
\hline 2 & $9-16-9.30$ & 5 s.d 7 & 3 \\
\hline 3 & $9.31-9.45$ & 8 s.d 11 & 4 \\
\hline 4 & $9.46-10.00$ & 12 s.d 15 & 4 \\
\hline 5 & $10.01-10.15$ & 16 s.d 18 & 3 \\
\hline 6 & $10.16-10.30$ & 19 s.d 22 & 4 \\
\hline 7 & $10.31-10.45$ & 23 s.d 25 & 3 \\
\hline 8 & $10.46-11.00$ & 26 s.d 29 & 4 \\
\hline 9 & $11.01-11.15$ & 30 s.d 32 & 3 \\
\hline 10 & $11.16-11.30$ & 33 s.d 37 & 5 \\
\hline 11 & $11.31-11.45$ & 38 s.d 39 & 2 \\
\hline 12 & $11.46-12.00$ & 40 s.d 42 & 3 \\
\hline 13 & $12.01-12.15$ & 43 s.d 44 & 2 \\
\hline
\end{tabular}

Sambungan dari tabel 12

\begin{tabular}{|c|c|c|c|}
\hline No & Interval & $\begin{array}{l}\text { Urutan } \\
\text { Pasien }\end{array}$ & $\begin{array}{c}\text { Total } \\
\text { pasien }\end{array}$ \\
\hline 14 & $12.16-12.30$ & 45 s.d 48 & 4 \\
\hline 15 & 12.31-12.45 & 49 s.d 53 & 5 \\
\hline 16 & $12.46-13.00$ & 54 s.d 58 & 5 \\
\hline
\end{tabular}

Tabel 13. Kedatangan Pasien untuk Kelompok Khusus Hari Jumat

\begin{tabular}{l|l|l|l}
\hline No & \multicolumn{1}{|c|}{ Interval } & Urutan Pasien & Total pasien \\
\hline 1 & $9.00-9.15$ & 1 s.d 2 & 2 \\
\hline 2 & $9-16-9.30$ & 3 & 1 \\
\hline 3 & $9.31-9.45$ & 4 & 1 \\
\hline 4 & $9.46-10.00$ & 5 s.d 6 & 2 \\
\hline 5 & $10.01-10.15$ & 7 & 1 \\
\hline 6 & $10.16-10.30$ & 8 & 1 \\
\hline 7 & $10.31-10.45$ & 9 & 1 \\
\hline 8 & $10.46-11.00$ & 10 s.d 11 & 2 \\
\hline 9 & $11.01-11.15$ & 12 s.d 13 & 2 \\
\hline 10 & $11.16-11.30$ & 14 & 1 \\
\hline 11 & $11.31-11.45$ & - & 0 \\
\hline 12 & $11.46-12.00$ & 15 & 1 \\
\hline 13 & $12.01-12.15$ & 16 & 1 \\
\hline 15 & $12.16-12.30$ & 17 s.d 18 & 2 \\
\hline 16 & $12.31-12.45$ & 19 s.d 20 & 2 \\
\hline
\end{tabular}

\section{SIMPULAN}

Sistem appointment scheduling pada Poliklinik Penyakit Dalam telah dapat dilakukan. Sembilan alternatif perbaikan telah dibuat dengan perlakukan yang berbeda beda pada masing-masing kelompok Server (2 Server dan 3 Server) serta delapan alternatif perbaikan yang telah dibuat dengan perlakukan yang berbeda beda untuk Hari Jumat khusus untuk poliklinik penyakit dalam. Setelah melakukan perbandingan hasil alternatif perbaikan didapatkan Alternatif 5, dengan data sebagai berikut.

Untuk kelompok Dua Server dengan menerapkan Alternatif 5 dapat mereduksi waktu tunggu dari 76,58 menit menjadi 3,94 menit atau mencapai optimasi sebesar 95\% apabila tidak ada keterlambatan dokter dan jika ada keterlambatan dokter, terjadi penurunan waktu tunggu dari 81,85 menit menjadi 52,25 menit (optimasi 50\%).

Untuk kelompok Tiga Server dengan menerapkan Alternatif 5 dapat mereduksi 
waktu tunggu dari 69,11 menit menjadi 6,52 menit atau mencapai optimasi sebesar $90 \%$ apabila tidak ada keterlambatan dokter dan jika ada keterlambatan dokter, terjadi penurunan waktu tunggu dari 107,20 menit menjadi 52,68 menit (optimasi 49\%).

Untuk Hari Jumat khusus dengan menerapkan alternatif 5 dapat mereduksi waktu tunggu dari 46,.48 menit menjadi 1,77 menit atau mencapai optimasi sebesar $96 \%$ apabila tidak ada keterlambatan dokter jika ada keterlambatan dokter, terjadi penurunan waktu tunggu dari 65,95 menit menjadi 49,91 menit (optimasi 28\%).

\section{DAFTAR PUSTAKA}

Dexter, F., 1999, Design of Appointment Systems for Preanesthesia Evaluation
Clinics to Minimize Patient Waiting Times: A Review of Computer Simulation and Patient Survey Studies, Anasthesia and Analgesia, 89, 925-931.

Gupta, D., and Denton, B., 2008, Appointment scheduling in Health Care: Challenges and Opportunities, IIE Transactions, 40:9, 800-819.

Jackson, J., Champberlin J. and Kroenke, K., 2001, Predictors of Patients Satisfaction, Social Science and Medicine 52: 609-620.

Swisher, R.J., Jacobson, S.H., Jun, J.B. and Balci,O., 2001, Modeling and Analyzing a physician clinic enviroment using discreteevent (visual) simulation, Computers and Operations Research, 28 (2), 105-125. 